
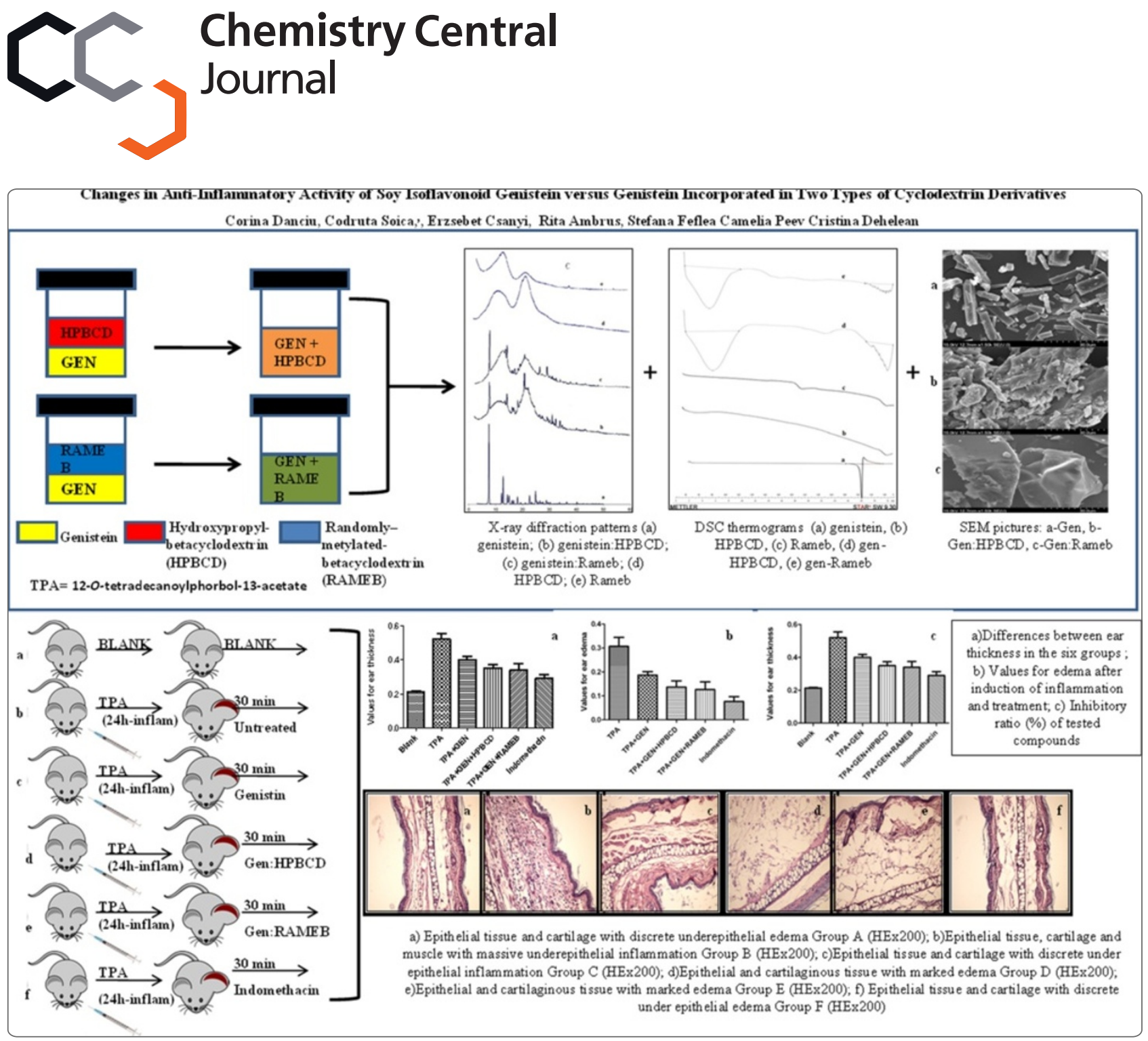

\title{
Changes in the anti-inflammatory activity of soy isoflavonoid genistein versus genistein incorporated in two types of cyclodextrin derivatives
}

Danciu et al. 


\title{
Changes in the anti-inflammatory activity of soy isoflavonoid genistein versus genistein incorporated in two types of cyclodextrin derivatives
}

\author{
CorinaTiulea Danciu ${ }^{1}$, Codruta Soica ${ }^{2 *}$, Erzsebet Csanyi ${ }^{3}$, Rita Ambrus ${ }^{3}$, Stefana Feflea ${ }^{1}$, Camelia Peev ${ }^{1}$ \\ and Cristina Dehelean ${ }^{4 *}$
}

\begin{abstract}
Background: The isoflavonoid genistein represents the major active compound from soybean, the vegetal product from Glycine max (Fabaceae). The aim of this study is to prove that genistein was incorporated in two semisynthetic cyclodextrins, beta-cyclodextrin derivatives: hydroxypropyl-beta-cyclodextrin and randomly-methylated-beta -cyclodextrin as well as to compare the anti-inflammatory activity of genistein with that of genistein incorporated in these two types of semisynthetic cyclodextrins.

Results: The animal studies were conducted on 8-week old C57BL/6 J female mice. Inflammation was induced in both ears of each mouse by topical application of 10 micrograms 12-O-tetradecanoylphorbol-3-acetate dissolved in $0.1 \mathrm{ml}$ solvent (acetone : dimethylsulfoxide in a molar ratio 9:1). Thirty minutes later treatment was applied. The inflammatory reaction was correlated with increased values in ear thickness. Treatment with genistein and genistein incorporated in the two cyclodextrins led to decreased values for ear thickness. Better anti-inflammatory action was found for the complexes of genistein. Both haematoxylin-eosin analysis and CD45 marker expression are in agreement with these findings.
\end{abstract}

Conclusions: Results allow concluding that genistein is an active anti-inflammatory phytocompound and its complexation with hydrophilic beta-cyclodextrin derivatives leads to a stronger anti-inflammatory activity.

Keywords: Genistein, Cyclodextrins, Inflammation, Haematoxylin-eosin, CD45, C57BL/6 J mouse

\section{Background}

Flavonoids (flavus $=$ yellow) are a class of secondary plant metabolites which function mainly as vegetal pigments, as antibiotic defence substances and as signal molecules for beneficial micro organisms in the rhizosphere [1]. Researchers continue to find new functions for this class of compounds, such as components of a healthy human diet $[1,2]$.

The isoflavonoid genistein (Gen) (4, 5, 7-trihydroxyisoflavone) (Figure 1), the aglycone of the heterosidegenistin,

\footnotetext{
* Correspondence: codrutasoica@umft.ro; cadehelean@umft.ro 2Department of Pharmaceutical Chemistry, "Victor Babes" University of Medicine and Pharmacy, 2 EftimieMurgu, Timisoara 300041, Romania ${ }^{4}$ Department of Toxicology, "Victor Babes" University of Medicine and Pharmacy, 2 EftimieMurgu, Timisoara 300041, Romania Full list of author information is available at the end of the article
}

represents a major active compound from soybean [2], the vegetal product from Glycine $\max$ (Fabaceae). Previous studies have demonstrated that genistein possesses many biological functions, such as preventive of coronary heart disease and osteoporosis, antioxidant, antineoplasic and anti-inflammatory compound [3-6].

Inflammation is a localized reaction of tissues in response to an aggressive action, characterized by redness, warmth, swelling, pain, and sometimes loss of mobility or function. Inflammation is considered a beneficial and necessary attempt of the organism to eliminate the aggressive agent and to start the healing process, which can consist in suppression of tumour initiation or progression. As a consequence, when the control mechanism of inflammation does not function properly and the inflammation persists, diseases including cancer may 


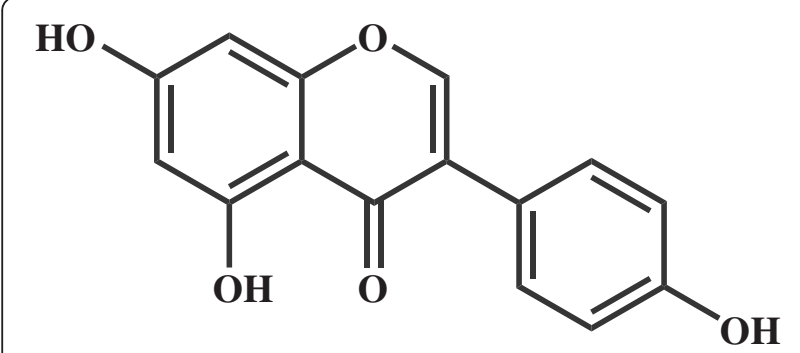

Figure 1 Chemical structure of genistein.

develop $[7,8]$. Previous studies have demonstrated that genistein and other flavonoids exhibit an antiinflammatory effect both for human and mouse skin, as well as inhibitory action against the activation of nuclear factor- $\mathrm{kB}$ and secretory phospholipase A2 [9-11].

Genistein shows a high solubility in organic solvents such as dimethylsulfoxide (DMSO), dimethylformamide, acetone and ethanol. Due to its chemical structure, it has, however, a very poor solubility in water, which drastically reduces its bioavailability [12]. Inclusion complexes are nowadays largely used in the pharmaceutical field in order to optimize the solubility, chemical stability and bioavailability of guest molecules. Recently, much interest has focused on cyclodextrins (CD), because of their remarkable ability to form host-guest inclusion complexes with a wide variety of molecules, changing the physical-chemical properties of the guests $[13,14]$. $\beta$-cyclodextrin derivatives are cyclic oligomers formed by seven units of glucose via $\alpha-(1,4)$-linkages, having a toroidal shape with hydrophobic cavity and hydrophilic exterior. Due to this specific structure, they act as molecular hosts for a large variety of guest molecules, both polar and non-polar, through non-covalent interactions [14].

The aim of this study is to compare the anti-inflammatory activity of genistein with the one of genistein incorporated in two ramified beta-cyclodextrins: hydroxypropyl-;betacyclodextrin (HPBCD) and randomly-metylated-beta-cyclodextrin (RAMEB); cyclodextrin-genistein products were physical-chemically analysed by X-ray diffraction, thermal analysis and electronic microscopy in order to evaluate the formation of real inclusion complexes. The study intends to examine the correlation between the increased water solubility of genistein, due to complexation, and its antiinflammatory activity on animal model.

\section{Results and discussion}

Genistein- $\beta-C D$ complexes were previously prepared, as reported in the literature [15], mainly through the insertion of the guest A-ring into the cyclodextrin cavity. The complexes of genistein with the natural beta-cyclodextrin proved a higher solubility and bioavailability compared to the drug alone [16]. Considering the rather low water solubility of natural $\beta-C D$, studies have been conducted on the complexation of genistein with derivatisedcyclodextrins [17]. To the best of our knowledge, no studies have been performed on the biological properties (i.e. anti-inflammatory activity) of genistein complexes with semisynthetic hydrophilic derivatives of $\beta-C D$.

Complexes were analysed by X-ray diffraction, differential scanning calorimetry (DSC) and scanning electron microscopy (SEM) in order to establish the true inclusion nature of the final product.

Figure 2 shows the diffraction patterns for genistein and its products with HPBCD and RAMEB. Genistein presents three major peaks at $2 \theta$ values of $7.51^{\circ}, 12.78^{\circ}$ and $24.81^{\circ}$ with a range of smaller peaks accompanying them. Both cyclodextrins, HPBCD and RAMEB, show no crystallinity at all, having an amorphous structure. All the characteristic peaks of genistein are highly reduced in case of genistein 1:2 products indicating a partial amorphisation of the product. The peak at $2 \theta$ value of $18.14^{\circ}$ shifts at $18.09^{\circ}$ in HPBCD complex. The peak at $2 \theta$ value of $19.33^{\circ}$ disappears completely at RAMEB complex and shifts at $19.23^{\circ}$ in case of HPBCD complex, while the peak at $2 \theta$ value of $21.13^{\circ}$ disappears in both cyclodextrin complexes. Two new peaks appear in case of HPBCD complex: at $2 \theta$ values of $14.83^{\circ}$ and $20.97^{\circ}$, indicative of an interaction between the drug and the cyclodextrin, accompanied by intimate changes of the lattice level. There is also a shift of the peak at $2 \theta$ value of $28.84^{\circ}$ at $28.76^{\circ}$ and $28.79^{\circ}$ in case of HPBCD and RAMEB complexes, respectively. The shifts of the peaks' position and the appearance of new peaks in the XRD patterns of genistein products indicate the possibility of formation of a solid form with different properties or inclusion complexes.

DSC analysis was used in order to reveal the interaction between the drug and its host molecules, HPBCD and RAMEB. When guest molecules are trapped inside cyclodextrin cavities, their physical-chemical parameters (such as melting, boiling, sublimation points) change: they either disappear or shift to other temperatures [18].

The DSC plot of pure genistein shows a crystalline state with a sharp endothermic peak at $303.66^{\circ} \mathrm{C}$ $\left(\Delta \mathrm{H}=142.73 \mathrm{~J} \cdot \mathrm{g}^{-1}\right)$ (Figure 3), which is attributed to its melting process. In the thermograms of both cyclodextrins no peaks were observed, confirming their amorphous structures; both cyclodextrins decompose above $300^{\circ} \mathrm{C}$. For both cyclodextrins, a broad endothermic band was observed at around $100^{\circ} \mathrm{C}$, which was related to the dehydration process. For the simple physical mixtures of pure genistein and cyclodextrins, thermograms showed a superposition of both components, with a partial amorphisation of the final products (not shown). The DSC 


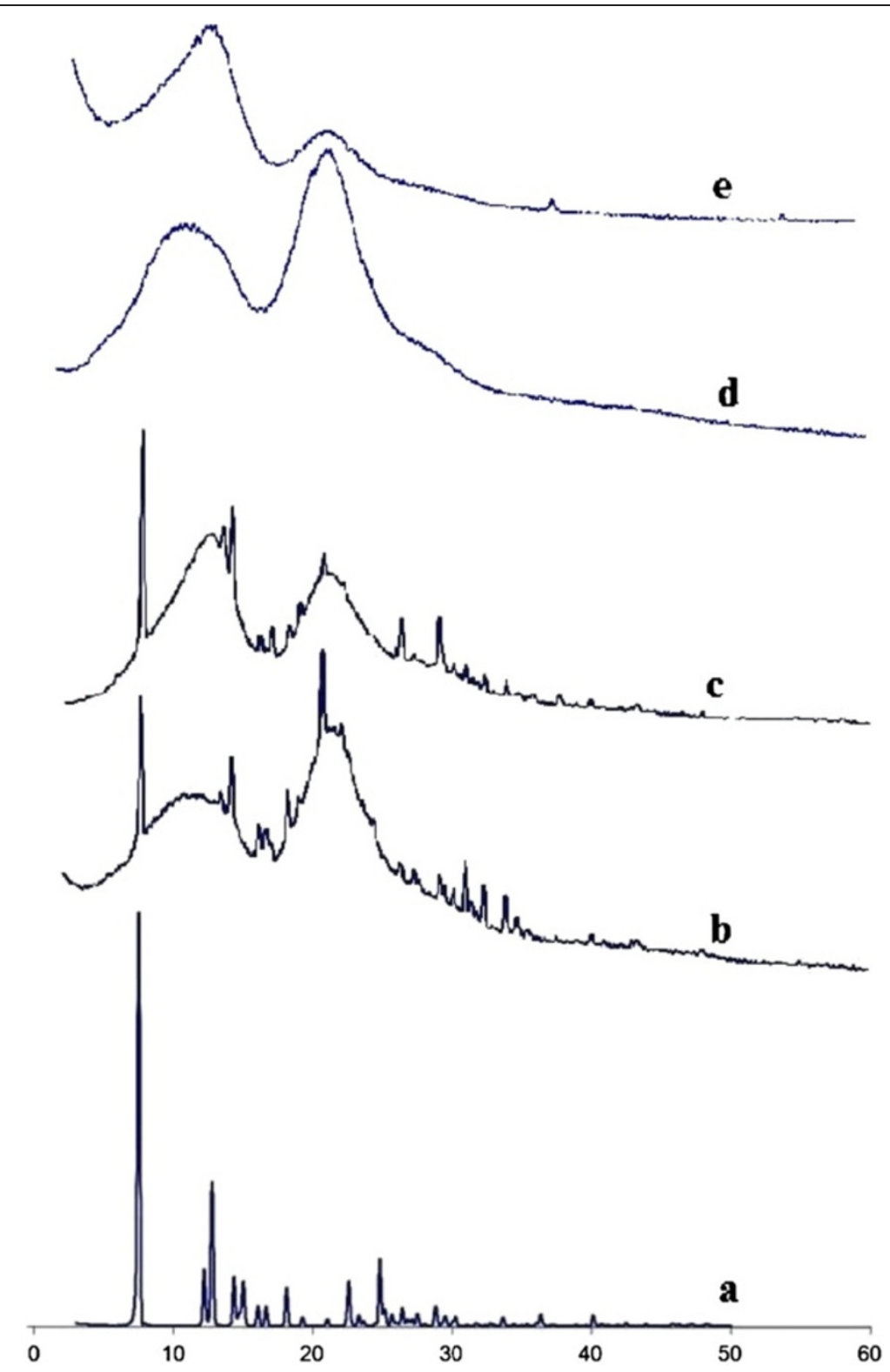

Figure 2 X-ray diffraction patterns. (a) genistein; (b) genistein: HPBCD; (c) genistein: RAMEB; (d) HPBCD; (e) RAMEB.

curves of the 1:2 complexes of genistein with HPBCD and RAMEB, respectively, showed the complete disappearance of genistein fusion peak, indicating the formation of amorphous aggregates and the possibility of inclusion complex formation between the two substances. The complexes decompose above $300^{\circ} \mathrm{C}$, similar to the pure cyclodextrins, a further evidence of the inclusion of genistein into the cyclodextrins' matrices.

The scanning electron microscopy images (Figure $4 \mathrm{a}, \mathrm{b}$, c) show a difference between the morphology of the pure substance genistein compared to its two complexes with HPBCD and RAMEB, respectively. This analysis confirms the fact that the complexation took place and physical interactions were produced.

Genistein consists of large, pure crystals with a smooth surface and a regular prismatic shape. The size of tetragonal particles is between $5-30 \mu \mathrm{m}$. The SEM pictures reveal the morphological changes of the crystals after complexation: the regular, smooth surface disappeared, and, because of the interaction between the drug and cyclodextrins, following the preparation procedure, aggregation can be seen. The cyclodextrins presumably cover the surface of genistein. HPBCD and RAMEB are amorphous materials and complexation agents, therefore 


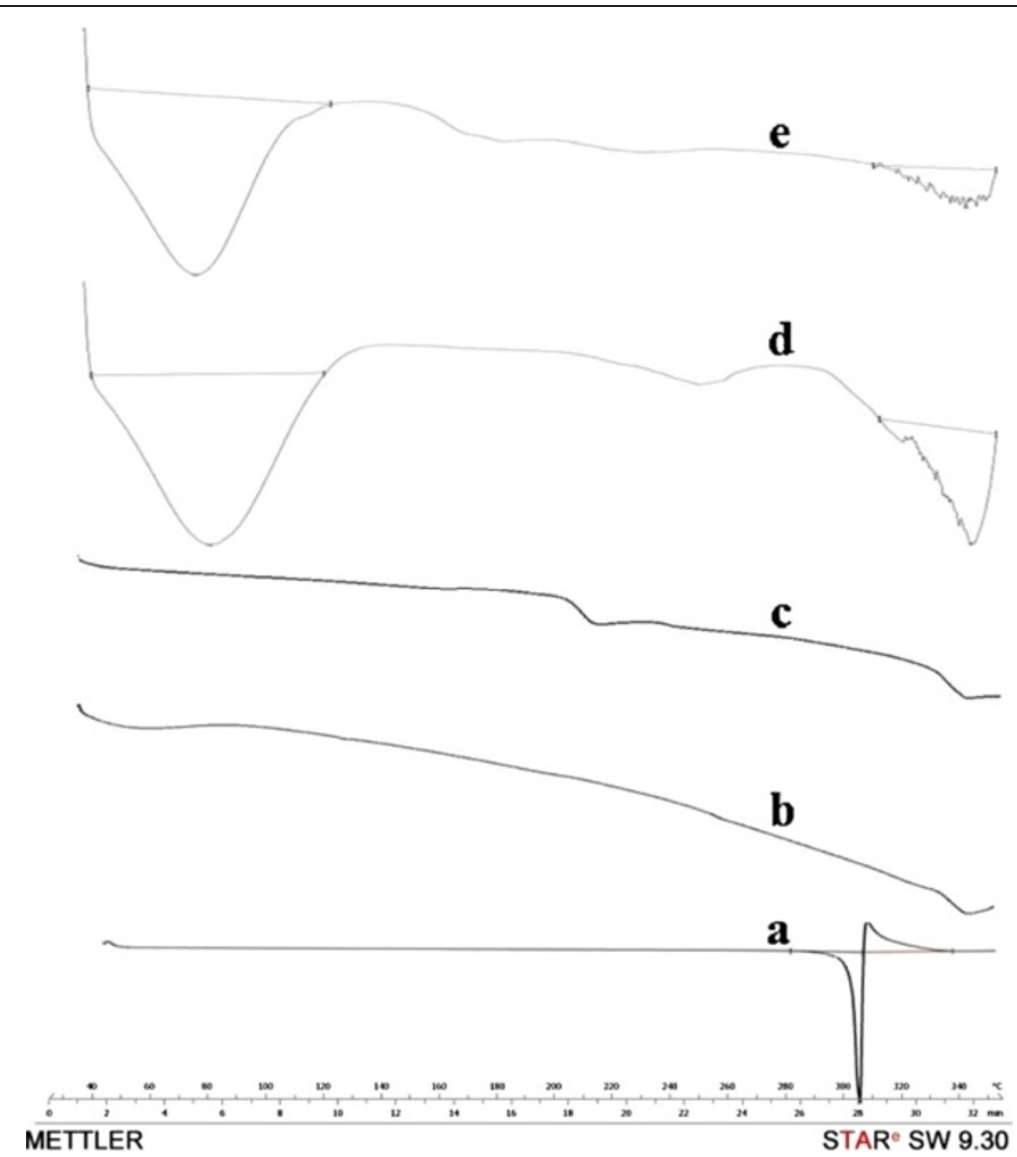

Figure 3 DSC thermograms. (a) genistein; (b) HPBCD; (c) RAMEB; (d) gen-HPBCD; (e) gen-RAMEB.

amorphisation and/or inclusion complexation of genistein is presumable. The regular shape of the drug is also affected; the amorphous HPBCD and RAMEB can be seen on the particle surface.

In order to be able to compare the anti-inflammatory activity of soy isoflavonoid genistein, which has already been confirmed by previous studies [9-11], to the one of genistein incorporated in HPBCD and RAMEB, inflammation was induced using the mouse ear model for inflammation and ear thickness was measured. Results presented in
Figure 5 indicate that the topical application of $10 \mu \mathrm{g} 12-\mathrm{O}-$ tetradecanoylphorbol-3-acetate (TPA) dissolved in $0.1 \mathrm{ml}$ solvent (acetone : DMSO in a molar ratio 9:1) to both the inner and outer ear surfaces causes a significant increase in ear thickness after 24 hours: $(0.52 \pm 0.06 \mathrm{~mm})$ compared to the one of mice in the blank group $(0.21 \pm 0.01 \mathrm{~mm})$. Experimental groups treated with genistein alone or incorporated in CDs showed significantly reduced ear oedema compared to group B, where TPA alone was applied on the mice ear. In case of treatment with pure genistein,

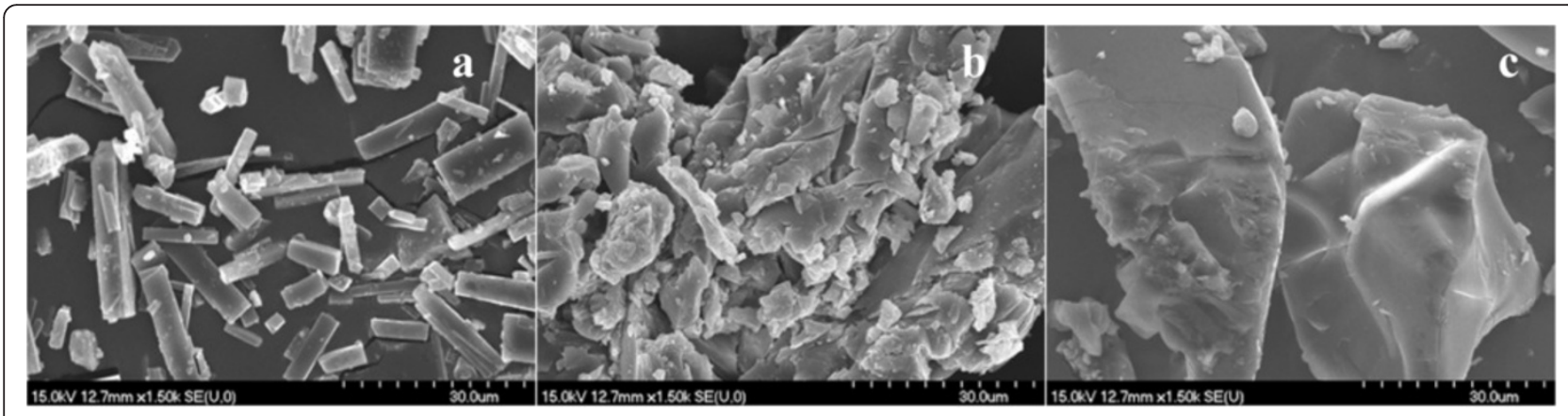

Figure 4 SEM pictures. $\mathbf{a}$ - Gen; $\mathbf{b}$ - Gen: HPBCD; $\mathbf{c}$ - Gen: RAMEB. 


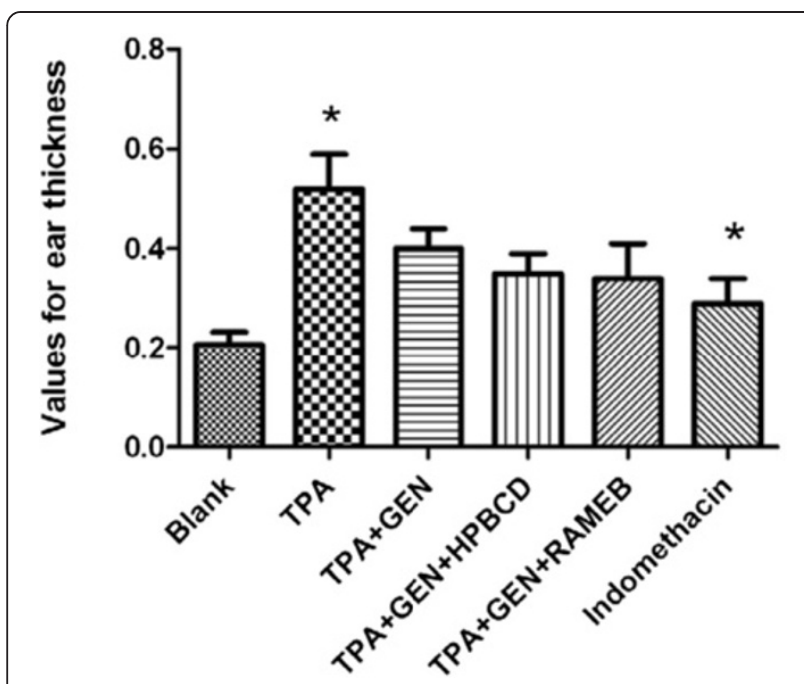

Figure 5 Differences between ear thicknesses in the six groups.

the average value for ear thickness decreased to $0.40 \pm 0.03 \mathrm{~mm}$. Smaller values, and therefore better antiinflammatory response, was found in case of treatment with the complexes: genistein : HPBCD $(0.35 \pm 0.04 \mathrm{~mm})$ and genistein : RAMEB $(0.34 \pm 0.06 \mathrm{~mm})$. Indomethacin was used as control and the average value of ear thickness in this case was $0.29 \pm 0.04 \mathrm{~mm}$. After measuring ear thickness for each group, values for oedema and inhibitory rate were calculated (Figure $6 \mathrm{a}, \mathrm{b}$ ). The average value for oedema induced by TPA alone was $0.31 \pm 0.06 \mathrm{~mm}, \mathrm{IR}=0 \%$, while the average value for oedema in case of treatment with genistein was $0.19 \pm 0.03 \mathrm{~mm}, \mathrm{IR}=38.71 \%$; for the $\mathrm{CD}$ complexes of genistein, the measured average values of oedema were: $0.14 \pm 0.04 \mathrm{~mm}, \mathrm{IR}=54.83 \%(\mathrm{HPBCD})$ and $0.13 \pm 0.06 \mathrm{~mm}, \mathrm{IR}=58.06 \%$ (RAMEB). Indomethacin led to average values of $0.08 \pm 0.04, \mathrm{IR}=74.19 \%$. These results allow to draw the conclusion that genistein has an antiinflammatory activity which becomes stronger for its complexes with hydrophilic CDs, but the values are smaller than in case of positive control using indomethacin.

After weighing the ears, morpho-pathological analyses were performed. Results can be seen in Figure $7 \mathrm{a}-\mathrm{f}$. Figure $7 \mathrm{a}$ presents histological aspect of a normal tissue while Figure 7b lays out changes in the tissue after inflammation was induced: massive oedema of the superficial and deep dermis, major destruction of the superficial dermis and complete lyses of the muscular layer were detected. Acute inflammation occurs in two overlapping stages: vascular and cellular. Oedema, an established marker of acute inflammation is present due to an increased blood vessel wall permeability followed by plasma extravasation [19-21]. Neutrophils ar capable of direct lyses of muscle cell membranes through a superoxide-dependent mechanism $[22,23]$. Data suggest that topical application of $10 \mu \mathrm{g}$ TPA dissolved in $0.1 \mathrm{ml}$ solvent to the inner and outer surfaces

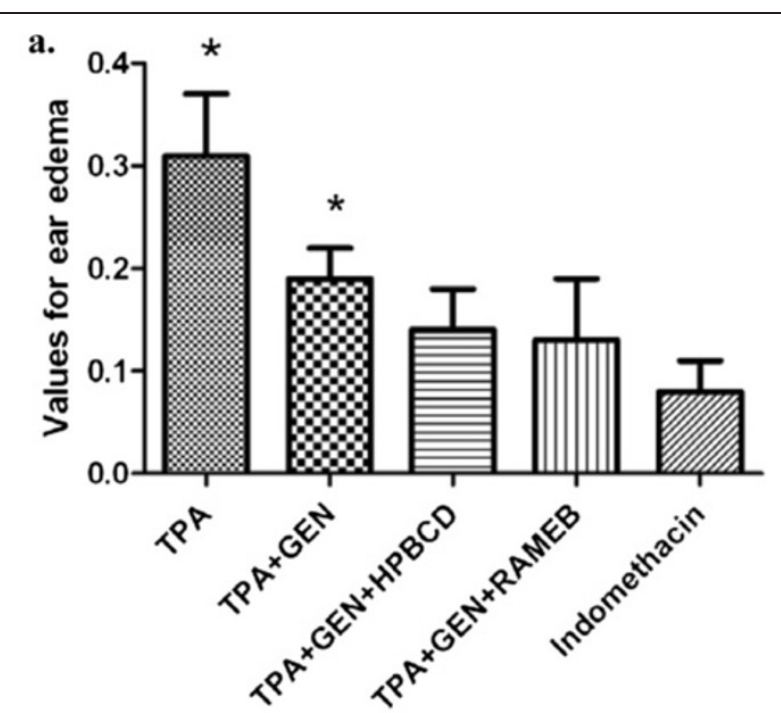

b.

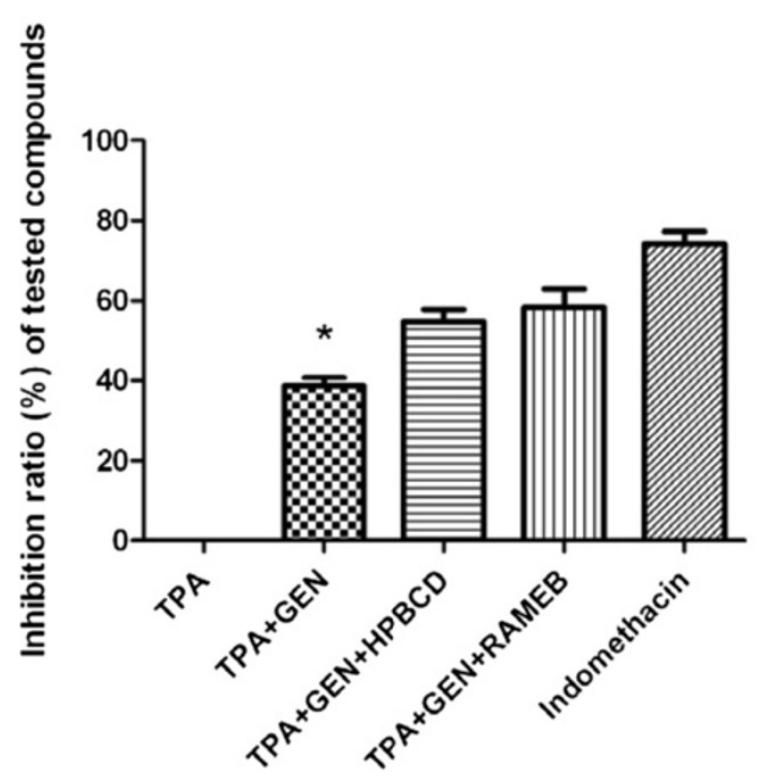

Figure 6a - Values for oedema after induction of inflammation and treatment; b - Inhibitory ratio (\%) of tested compounds.

of the ear is a reliable and easily reproducible model for acute inflammation in experimental animals [24-26]. When genistein was applied, Figure $7 \mathrm{c}$, massive oedema of the deep dermis was still present but only a partial destruction of the superficial dermis and of the underlying muscle cells could be detected. Inhibition of TPA-induced inflammation might be associated with the genistein's capacity to suppress the production of reactive oxygen species and other inflammatory mediators [3]. Results are consistent with the findings of other groups: Bandara et al. [10] underlined the anti-inflammatory activity of topical isoflavonoids, using UVB irradiation to induce inflammation in 

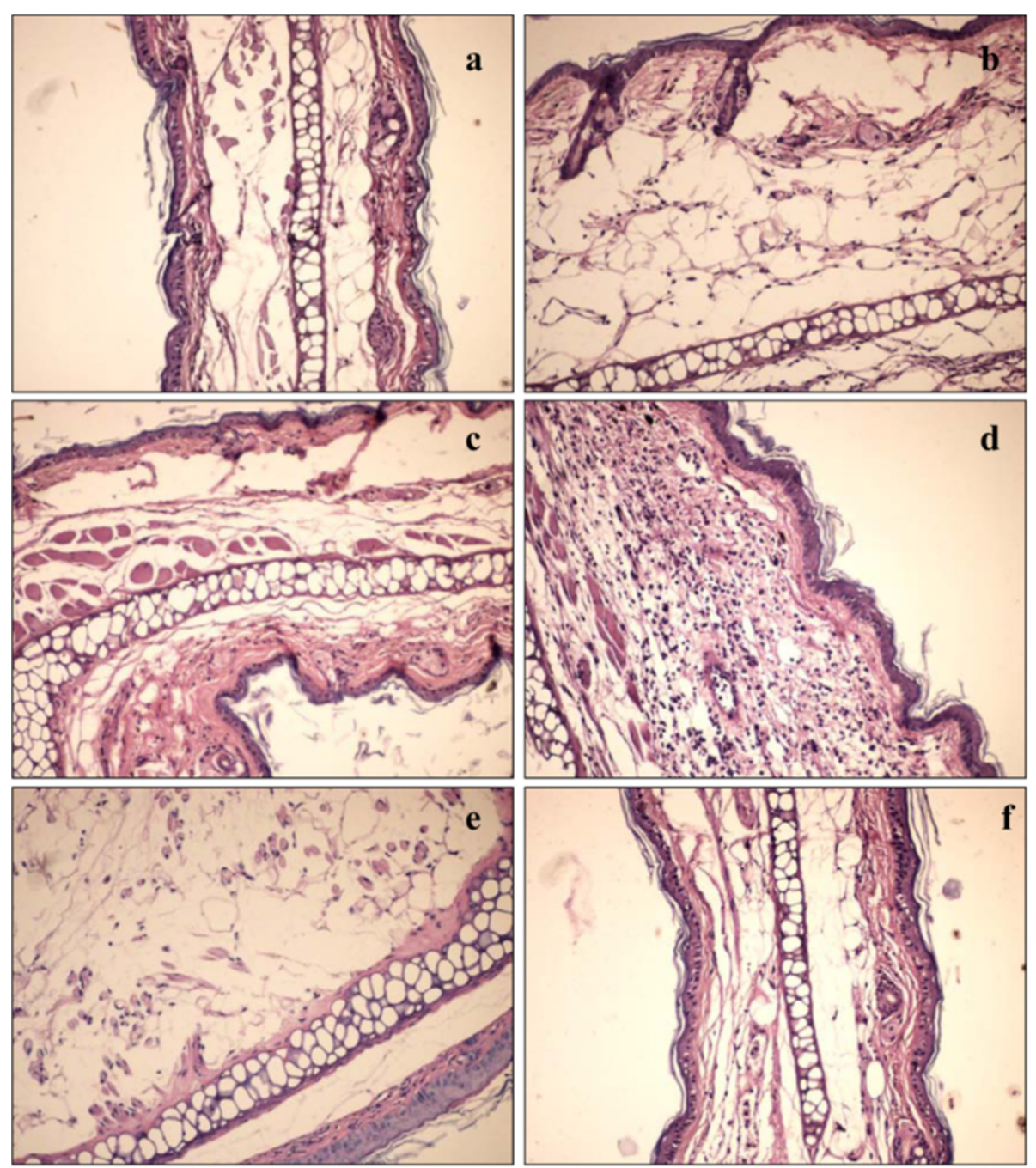

Figure 7 Histological analysis. a) Normal tissue - Group A (HEx200); b) Massive oedema of the superficial and deep dermis. Major destruction of the superficial dermis. Complete lyses of the muscular layer- Group B (HEX200); c) Massive oedema of the deep dermis. Partial destruction of the superficial dermis. Partial destruction of the underlying muscle cells- Group C (HEX200); d) Rich polymorphous inflammatory infiltrate that increases in thickness the sub epithelial dermis without inflammatory infiltrate in epithelial tissue-Group D (HEX200); e) Epithelial and cartilaginous tissue with marked edema Group E (HEx200); f) Loose stroma, oedematous, with low cellularity-Group F (HEX200).

mouse skin. Huang et al., 2010 [27], noticed the positive effect of soy isoflavone extract from soybean cake for the protective effects against UVB-induced damage, including inflammation. An improved anti-inflammatory activity of genistein was detected when genistein was incorporated in the two $\beta$-CDs. In case of the complex genisten : HPBCD, Figure $7 \mathrm{~d}$, haematoxylin-eosin (H\&E) analysis detected a rich polymorphous inflammatory infiltrate that increased in thickness the sub epithelial dermis without the presence of an inflammatory infiltrate in the epithelial tissue, while in case of the complex genistein : RAMEB, Figure 7e, H\&E analysis detected an epithelial and cartilaginous tissue with marked oedema. Inclusion complexes of cyclodextrins with nonpolar drugs represent a topic of high interest in pharmaceutical research, for providing the possibility to increase the water solubility, stability and bioavailability of the guest drugs $[14,17,28,29]$. Genistein bioavailability can be increased by complexation with CDs [30]. Zhao et al. [31] found an enhanced bioavailability of soy isoflavones by complexation with two commercially available dendrimers.

For the control group, mice treated with indomethacin, Figure $7 f$, a loose stroma, oedematous, with low cellularity was detected. Indomethacin is a consecrated typical nonsteroidal anti-inflammatory compound [32,33].

In order to observe some of the cellular events, more specific migration of leucocytes at the site of injury, expression of the marker CD45 was analysed (Figure 8 a-f). $\mathrm{CD} 45$, a transmembranar leukocyte-specific protein tyrosine phosphatase, is an abundant cell surface glicoprotein 
on lymphocytes. It exhibits multiple splicing isoforms and modulates the function of the haematopoietic cells. CD45 is also called the common leukocyte antigen $[34,35]$. Because inflammation is characterised by a transfer of plasma and leucocytes from the blood into the damaged tissue [36], CD45 is a good marker to differentiate the degree of inflammation. Acute inflammation is mediated by granulocytes, mainly neutrophils $[37,38]$ while macrophages together with lymphocytes are involved in the production mechanism of chronic inflammation $[39,40]$. In this study one can observe the weak expression of CD45 in case of group A, blank, and group F, mice treated with indomethacin, a classical anti-inflammatory compound $[32,33]$ in contrast with the strong expression of the marker in case of group B, mice on which TPA in acetone was administered. Due to an increased presence of leucocytes in this group, again one can confirm that TPA is a good inductor of inflammation. The expression of the marker is reduced in case of group $\mathrm{C}$, mice treated with genistein, compared to group B, but higher than the expression in group F. This allows us to assert that genistein possesses anti-inflammatory proprieties, but milder than the ones of indomethacin. Regarding the presence of leucocytes in case of group D, mice treated with genistein incorporated in HPBCD, and group E, mice treated with genistein incorporated in RAMEB, their number is quite similar with slight increased values in case of group E. In both cases the expression is weaker than in case of group $\mathrm{C}$, confirming again the findings that genistein incorporated in $\beta$-CDs presents a greater bioavailability, translated in a stronger anti-inflammatory effect.

\section{Conclusions}

As conclusion, genistein can be reconsidered as an active anti-inflammatory phytocompound on C57BL/6 J animal model. Complexation of this active phytocompound with
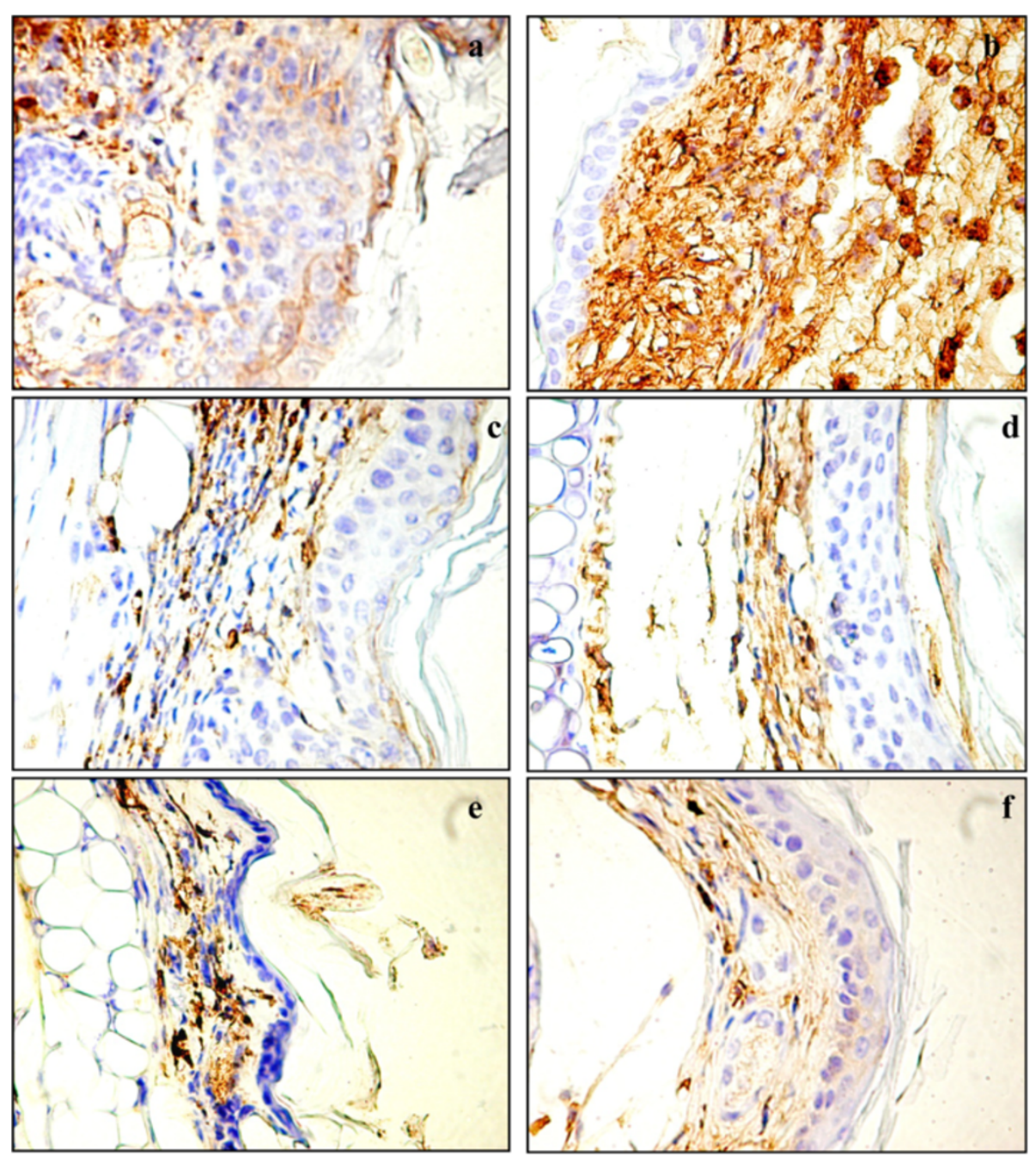

Figure 8 Expression of the marker CD45 in the different groups (x 400). a)- Group A; b)- Group B; $\mathbf{c}$ )- Group C; d)- Group D; e)- Group E; f)- Group F. 
ramified $\beta-C D$ derivatives was feasible and led to a stronger anti-inflammatory activity, proving to be a good method to improve the water solubility of genistein in order to obtain a better therapeutic response. These findings are of special interest since pharmaceutical formulations that produce increased drug concentration at the delivery site represent a better therapeutic option for patients.

\section{Methods \\ Reagents}

Genistein was purchased from Extrasynthese (France, purity $>95 \%$ ), hydroxylpropyl-beta-cyclodextrin (HPBCD) and randomly-metylated-beta-cyclodextrin (RAMEB) from Cyclolab Hungary, 12-O-tetradecanoylphorbol-13-acetate (TPA) from Sigma Aldrich, Germany. All substances were used as received.

\section{Preparation of complexes}

Different methods were applied for the preparation of the inclusion complexes:

- simple powder mixing, using a mortar and a pestle;

- kneading with a 50\% (w/w) water : ethanol solution until the bulk of solvent evaporated and a paste-type product was formed; the mixture was then dried at room temperature for 24 hours and put in the oven, at $105^{\circ} \mathrm{C}$, for several hours until reaching constant weight. The final product was pulverized and sieved.

All the binary products were prepared using 1:2 genistein : $\mathrm{CD}$ molar ratio $\left(\mathrm{Mw}_{\mathrm{Gen}}=270,25, \mathrm{Mw}_{\mathrm{HPBCD}}=1396\right.$, $\left.M w_{\text {Rameb }}=1303\right)$. The molar ratio of $1: 2$ was chosen in order to achieve a better water solubility for genistein.

\section{Differential scanning calorimetry (DSC)}

The DSC measurements were made with a Mettler Toledo DSC $821^{\mathrm{e}}$ thermal analysis system with the STAR thermal analysis program V9.1 (Mettler Inc., Schwerzenbach, Switzerland). Approximately $2-5 \mathrm{mg}$ of genistein or its product was examined in the temperature range between $25^{\circ} \mathrm{C}$ and $350^{\circ} \mathrm{C}$. The heating rate was $5^{\circ} \mathrm{C} \mathrm{m^{-1 }}$. Argon was used as carrier gas, at a flow rate of $10 \mathrm{lh}^{-1}$ during the DSC investigation.

\section{Scanning electron microscopy (SEM) assay}

The shape and surface characteristics of genistein and complex were visualized using a scanning electron microscope (Hitachi S4700, Hitachi Scientific Ltd., Japan). The samples were sputter coated with goldpalladium under an argon atmosphere using a gold sputter module in a high vacuum evaporator and the samples were examined using SEM set at $15 \mathrm{kV}$.

\section{X-ray diffraction}

X-Ray-diffraction patterns were obtained on a Philips PW 1710 diffractometer, where the tube anode was $\mathrm{Cu}$ with $K \alpha=1.54242 \AA$. The pattern was collected with a tube voltage of $50 \mathrm{kV}$ and $40 \mathrm{~mA}$ of tube current in step scan mode (step size 0.035 , counting time $1 \mathrm{~s}$ per step).

\section{Animal studies}

Ethical statement: The work protocol followed all NIAH-National Institute of Animal Health rules: animals were maintained during the experiment in standard conditions: $12 \mathrm{~h}$ light-dark cycle, food and water ad libitum, temperature $24^{\circ} \mathrm{C}$, humidity above $55 \%$. The experiment was conducted according to the rules of the Ethical Committee of UMF "Victor Babes" Timisoara.

Animal studies were conducted on 8-week old C57BL/ $6 \mathrm{~J}$ female mice. Mice were purchased from Charles River (Sulzfeld, Germany). The number of mice included in the study was forty-eight (48), divided into six groups as follows:

- group A: blank group

- group B: mice on which TPA in acetone/DMSO was applied on the ear

- group C: mice on which TPA in acetone/DMSO and genistein (30 minutes later) were applied on the ear

- group D: mice on which TPA in acetone/DMSO and genistein : HPBCD 1:2 (30 minutes later) were applied on the ear

- group E: mice on which TPA in acetone/DMSO and genistein : RAMEB 1:2 (30 minutes later) were applied on the ear

- group F: mice on which TPA in acetone/DMSO and indomethacin (30 minutes later) were applied on the ear as control.

\section{Inflammation protocol}

Inflammation was induced in both ears of each mouse by the topical application of $10 \mu \mathrm{g}$ TPA dissolved in $0.1 \mathrm{ml}$ acetone : DMSO in a molar ratio 9:1 to both the inner and outer ear surfaces. Thirty minutes after the application of TPA, the inner and outer surface of each ear was treated with $2 \mathrm{mg}$ of genistein, or the equivalent quantity of $2 \mathrm{mg}$ genistein corresponding from the complex Gen : HPBCD and Gen : RAMEB. The same quantity of indomethacin, $2 \mathrm{mg}$, was used as control. The solvent was acetone : DMSO in a molar ratio 9:1 and the quantity administered was $0.1 \mathrm{ml}$.[25,41] After 24 hours from the moment of application skin inflammation was induced, indicated by the increase of ear thickness on C57BL6/J mice. Ear thickness was measured with callipers, before treatment (value a) and 24 hours after TPA application (value $\mathrm{b}=$ TPA alone and value $\mathrm{c}=$ TPA + active substance). The experiment was repeated 
three times and results are expressed as mean \pm standard deviation. The following values were also calculated:

- Oedema X induced by TPA alone (b-a),

- Oedema Y induced by TPA plus a sample (c-a),

- Inhibitory rate (\%) [(Oedema X-Oedema Y)/Oedema $\mathrm{X}] \mathrm{x} 100$.

After that, mice were killed by cervical dislocation and $6 \mathrm{~mm}^{2}$ diameter ear punch biopsies were collected and H\&E analysis was carried out $[24,26]$. The Prism software package (Graph Pad Prism 4.03 for Windows) was used for data presentation. The experiment was repeated three times and results are presented as mean $\pm \mathrm{SD}$. Paired Student's $t$ tests was applied to evaluate statistical significance $(*, p<0.05 ; * *, p<0.01 ;$ and $* * *$, $p<0.001)$.

\section{Histology}

For the histological analysis, tissue samples (skin) were fixed in $10 \%$ formalin solution, embedded in paraffin and cut at 4 microns. Finally, deparaffinized, the samples were stained with H\&E (hematoxylin-eosin) and microscopically analysed. Immunohistochemistry was performed by using CD45 antibodies against inflammatory cells from the dermis. After dewaxing and rehydration, the sections were incubated with CD45 for 30 minutes, and then, the antigen-antibody reaction was detected by using an avidin biotin system from Novocastra. Visualization of the final product was done by using 3,3'diaminobenzidine as chromogen. Counterstain was performed with Lille's modified haematoxylin.

\section{Competing interests}

Authors declare no competing interests.

\section{Authors' contributions}

$\mathrm{CD}(\mathrm{T})$ carried out the design of the study, participated in animal studies and drafted the manuscript. CS carried out preparation of cyclodextrin complexes, physico-chemical analysis and performed statistical analysis and final interpretation of results. EC and RA participated in physico-chemical analysis. SF and CP carried out the immunoassays. CD participated in the study's design and coordination and helped to draft the manuscript. All authors read and approved the final manuscript.

\section{Author details}

"Department of Pharmacognosy, "Victor Babes" University of Medicine and Pharmacy, 2 EftimieMurgu, Timisoara 300041, Romania. ${ }^{2}$ Department of Pharmaceutical Chemistry, "Victor Babes" University of Medicine and Pharmacy, 2 EftimieMurgu, Timisoara 300041, Romania. ${ }^{3}$ Department of Pharmaceutical Technology, University of Szeged, 6 Eotvos u., Szeged H-6720, Hungary. ${ }^{4}$ Department of Toxicology, "Victor Babes" University of Medicine and Pharmacy, 2 EftimieMurgu, Timisoara 300041, Romania.

Received: 24 April 2012 Accepted: 8 June 2012

Published: 20 June 2012

\section{References}

1. Dixon RA, Steele CL: Flavonoids and isoflavonoids - a gold mine for metabolic engineering. Trends Plant Sci 1999, 10:394-400.
2. Messina M: A brief historical overview of the past two decades of soy and isoflavone research. J Nutr 2010, 140:1350S-1354S.

3. Wei $H$, Bowen $R$, Zhang $X$, Lebwohl M: Isoflavone genistein inhibits the initiation and promotion of two-stage skin carcinogenesis in mice. Carcinogenesis 1998, 19:1509-1514.

4. Dalais FS, Ebeling PR, Kotsopoulos D, McGrath BP, Teede HJ: The effects of soy protein containing isoflavones on lipids and indices of bone resorption in postmenopausal women. Clin Endocrinol (Oxf) 2003, 58:704-709.

5. Neelakandan C, Chang T, Alexander T, Define L, Evancho-Chapman M, Kyu $T$ : In vitro evaluation of antioxidant and anti-inflammatory properties of genistein-modified hemodialysis membranes. Biomacromolecules 2011, 12:2447-2455

6. Gottstein N, Ewins BA, Eccleston C, Hubbard GP, Kavanagh IC, Minihane A-M, Weinberg PD, Rimbach G: Effect of genistein and daidzein on platelet aggregation and monocyte and endothelial function. Brit J Nutr 2003, 89:607-615.

7. Scott A, Khan KM, Cook JL, Duronio V: What is "inflammation"? Are we ready to move beyond Celsus? Br J Sports Med 2004, 38:248-249.

8. Prasad S, Phromnoi K, Yadav VR, Chaturvedi MM, Aggarwal BB: Targeting inflammatory pathways by flavonoids for prevention and treatment of cancer. Planta Med 2010, 76:1044-1063.

9. Hämäläinen $M$, Nieminen R, Vuorela $P$, Heinonen M, Moilanen E: Antiinflammatory effects of flavonoids: genistein, kaempferol, quercetin, and daidzein inhibit STAT-1 and NF-kappaB activations, whereas flavone, isorhamnetin, naringenin, and pelargonidin inhibit only NF-kappaB activation along with their inhibitory effect on iNOS expression and NO production in activated macrophages. Mediators Inflamm 2007, 2007:45673.

10. Bandara M, Arun SJ, Allanson M, Widyarini S, Chai Z, Reeve VE: Topical isoflavonoids reduce experimental cutaneous inflammation in mice. Immunol Cell Biol 2010, 88:727-733.

11. Dharmappa KK, Mohamed R, Shivaprasad HV, Vishwanath BS: Genistein, a potent inhibitor of secretory phospholipase A2: a new insight in down regulation of inflammation. Inflammopharmacol 2010, 18:25-31.

12. Tang J, Xu N, Ji H, Liu H, Wang Z, Wu L: Eudragit nanoparticles containing genistein: formulation, development, and bioavailability assessment. Int J Nanomed 2011, 6:2429-2435.

13. Del Valle EMM: Cyclodextrins and their uses: a review. Process Biochem 2004, 39:1033-1046.

14. Arun R: Ashok Kumar CK, Sravanthi WVNSS: Cyclodextrins as Drug Carrier Molecule: A Review. Sci Pharm 2008, 76:567-598.

15. Xavier CR, Silva APC, Schwingel LC, Borghetti GS, Koester LS, Mayorga P, Teixeira HF, Bassani VL, Lula IS, Sinisterra RD: Improvement of genistein content in solid genistein/beta-cyclodextrin complexes. Quim Nova 2010, 33:587-590.

16. Lee SH, Kim YH, Yu HJ, Cho NS, Kim TH, Kim DC, Chung CB, Hwang Yl, Kim $\mathrm{KH}$ : Enhanced bioavailability of soy isoflavones by complexation with beta-cyclodextins in rats. Biosci Biotech Biochem 2007, 71:2927-2933.

17. Stancanelli R, Guardo M, Cannava C, Guglielmo G, Ficarra P, Villari V, Micali N, Mazzaglia A: Amphiphiliccyclodextrins as nanocarriers of genistein: a spectroscopic investigation pointing out the structural properties of the host/drug complex system. J Pharm Sci 2010, 99:3141-3149.

18. Marques Cabral HM, Hadgraft J, Kellaway IW: Studies of cyclodextrin inclusion complexes. I. The salbutamol-cyclodextrin complex as studied by phase solubility and DSC. Int J Pharm 1990, 63:259-266.

19. Moos MP, Mewburn JD, Kan FW, Ishii S, Abe M, Sakimura K, Noguchi K, Shimizu T, Funk CD: Cysteinyl leukotriene 2 receptor-mediated vascular permeability via transendothelial vesicle transport. FASEB J 2008, 22:4352-4362

20. Serhan CN: Controlling the resolution of acute inflammation: a new genus of dual anti-inflammatory and proresolving mediators. J Periodontol 2008, 79:1520-1526.

21. Kenne $E$, Lindbom L: Imaging inflammatory plasma leakage in vivo. Thromb Haemost 2011, 105:783-789.

22. Nguyen HX, Tidball JG: Expression of a muscle-specific, nitric oxide synthase transgene prevents muscle membrane injury and reduces muscle inflammation during modified muscle use in mice. J Physiol 2003, 550:347-356.

23. Tidball JG: Inflammatory processes in muscle injury and repair. Am J Physiol Regul Integr Comp Physiol 2005, 288:R345-R353. 
24. Al-Reza SM, Yoon Jl, Kim HJ, Kim JS, Kang SC: Anti-inflammatory activity of seed essential oil from Zizyphus jujube. Food Chem Toxicol 2010, 48:639-643.

25. Bralley EE, Greenspan P, Hargrove JL, Wicker L, Hartle DK: Topical antiinflammatory activity of Polygonumcuspidatum extract in the TPA model of mouse ear inflammation. J Inflamm 2008, 5:1. doi:10.1186/1476-9255-5-1.

26. Lee do Y, Choi G, Yoon T, Cheon MS, Choo BK, Kim HK: Anti-inflammatory activity of Chrysanthemum indicum extract in acute and chronic cutaneous inflammation. J Ethnopharmacol 2009, 123:149-154.

27. Huang CC, Hsu BY, Wu NL, Tsui WH, Lin TJ, Su CC, Hung FC: Antiphotoaging effects of soy isoflavone extract (aglycone and acetylglucoside form) from soybean cake. Int J Mol Sci 2010, 12:4782-4795

28. Crupi V, Majolino D, Paciaroni A, Stancanelli R, Venuti V: Influence of the "Host-Guest" interactions on the mobility of Genistein/ $\beta$-Cyclodextrin inclusion complex. J Phys Chem B 2009, 113:11032-11038.

29. Stancanelli R, Mazzaglia A, Tommasini S, Calabrò ML, Villari V, Guardo M, Ficarra P, Ficarra R: The enhancement of isoflavones water solubility by complexation with modified cyclodextrins: a spectroscopic investigation with implications in the pharmaceutical analysis. J Pharm Biomed Anal 2007, 44:980-984.

30. Daruházi ÁE, Szente L, Balogh B, Mátyus P, Béni S, Takács M, Gergely A, Horváth P, Szőke E, Lemberkovics E: Utility of cyclodextrins in the formulation of genistein: Part 1. Preparation and physicochemical properties of genistein complexes with native cyclodextrins. J Pharm Biomed Anal 2008, 48:636-640.

31. Zhao C, Wang Y, Su Y, Zhang H, Ding L, Yan X, Zhao D, Shao N, Ye X, Cheng $Y$ : Inclusion complexes of isoflavones with two commercially available dendrimers: Solubility, stability, structures, release behaviors, cytotoxicity, and anti-oxidant activities. Int J Pharm 2011, 421:301-309.

32. Bernardi A, Zilberstein A, Jäger E, Campos MM, Morrone FB, Calixto JB, Pohlmann AR, Guterres SS, Battastini A: Effects of indomethacin-loaded nanocapsules in experimental models of inflammation in rats. $\mathrm{Br} J$ Pharmacol 2009, 158:1104-1111.

33. Castro P, Nasser H, Abrahao A, Dos Reis LC, Rica I, Valenca SS, Rezende DC Quintas LE, Cavalcante MC, Porto LC, Koatz VL: Aspirin and indomethacin reduce lung inflammation of mice exposed to cigarette smoke. Biochem Pharmacol 2008, 77:1029-1039.

34. Cross JL, Kott K, Miletić T, Johnson P: CD45 Regulates TLR-Induced Proinflammatory Cytokine and IFN- $\beta$ Secretion in Dendritic Cells. $\mathrm{J}$ Immunol 2008, 180:8020-8029.

35. Cosenza-Nashat MA, Kim MO, Zhao ML, Suh HS, Lee SC: CD45 Isoform Expression in Microglia and Inflammatory Cells in HIV-1 Encephalitis. Brain Pathol 2006, 16:256-265.

36. Latha MS, Latha KP, Vagdevi HM, Virupaxappa SB: Anti inflammatory activity of Mangifera indica L. Var. Rasapuri Root extracts. J Chem Pharm Res 2012, 4:333-336.

37. Mukaida N, Matsumato T, Yokoi K, Harada A, Matsushima K: Inhibition of neutrophil-mediated acute inflammatory injury by an antibody against interleukin-8 (IL-8). Inflamm Res 1998, 47(Suppl 3):S151-S157.

38. Serhan CN, Savill J: Resolution of inflammation: the beginning programs the end. Nat Immunol 2005, 6:1191-1197.

39. Davies $P, A l l i s o n ~ A C:$ The macrophage as a secretory cell in chronic inflammation. Agents Actions 1976, 6:60-74

40. Trowbridge $\mathrm{HO}$ : Immunological aspects of chronic inflammation and repair. J Endodont 1990, 16:54-61.

41. Yasukawa K, Takido M, Matsumoto T, Takeuchi M, Nakagawa S: Sterol and triterpene derivatives from plants inhibit the effects of a tumor promoter, and sitosterol and betulinic acid inhibit tumor formation in mouse skin two-stage carcinogenesis. Oncology 1991, 48:72-76.

doi:10.1186/1752-153X-6-58

Cite this article as: Danciu et al:: Changes in the anti-inflammatory activity of soy isoflavonoid genistein versus genistein incorporated in two types of cyclodextrin derivatives. Chemistry Central Journal 2012 6:58.

Publish with ChemistryCentral and every
scientist can read your work free of charge
"Open access provides opportunities to our
colleagues in other parts of the globe, by allowing
anyone to view the content free of charge."
W. Jeffery Hurst, The Hershey Company.
- available free of charge to the entire scientific community
- peer reviewed and published immediately upon acceptance
- cited in PubMed and archived on PubMed Central
- yours - you keep the copyright
submit your manuscript here:
htt://www.chemistrycentral.com/manuscript/

